\title{
https://doi.org/10.46813/2021-136-061 MAGNETIC FIELD DYNAMICS IN PLASMA OPENING SWITCH
}

\author{
O.V. Manuilenko*, I.N. Onishchenko, A.V. Pashchenko, I.A. Pashchenko, V.A. Soshenko, \\ V.G. Svichensky, V.B. Yuferov, B.V. Zajtsev \\ National Science Center "Kharkov Institute of Physics and Technology", Kharkiv, Ukraine \\ E-mail:ovm@kipt.kharkov.ua
}

Computer simulations for magnetic field penetration into plasma of plasma opening switch (POS), and current loop formation in it are presented for various initial plasma densities, currents, and POS geometries. It is shown that the current loop dynamics in the POS is determined by the fast magnetic field penetration in plasma due to the Hall effect. The strong dependence of the current loop longitudinal velocity on the transverse coordinate, together with the influence of the boundary conditions at the POS cathode and anode, lead to the formation of the narrow Sshaped current loop even in a homogeneous plasma. It is shown that the control parameters influencing the dynamics of the magnetic field and the motion of the current loop in the POS are the initial plasma density, driving current and cathode radius. The POS resistance is calculated for wide range of initial plasma densities, currents, and cathode radiuses. It is shown, that POS resistance is proportional to the total current, inversely proportional to plasma density, and is in the range $10^{-3} \ldots 1 \Omega$ for plasma densities $10^{12} \ldots 10^{15} \mathrm{~cm}^{-3}$.

PACS: 52.75.-d, 52.75.Kq, 52.40.Hf, 52.65,+z, 52.70.Kz, 94.20.wc

\section{INTRODUCTION}

A plasma opening switch (POS) is a plasma bridge between two electrodes, in most cases in vacuum coaxial line (Fig. 1). An inner electrode is usually a cathode and outer electrode is an anode. POSes are used for voltage multiplication in pulsed-power science and technology including high-current pulsed electron accelerators. The high-voltage pulse generator with POS is a LC circuit closed through the POS. One end of the POS is usually connected to capacitive energy storage, the other - to a load. When energy storage is turned on, the current in the line increasing in time is closed through the POS, the electrical energy of the capacitive energy storage $\mathrm{CU}_{\mathrm{o}}{ }^{2} / 2$ is converted into magnetic energy $\mathrm{LI}^{2} / 2$. After some time, the impedance of the plasma bridge increases sharply, the current is quickly decreased, a voltage pulse appears $\mathrm{U}_{\mathrm{POS}} \sim \mathrm{LdI} / \mathrm{dt}>\mathrm{U}_{\mathrm{o}}$, and the accumulated energy is transferred to the load. The POS opening time is much shorter (typically by $3-12$ times) than the rise time of the current pulse. The shortening of the pulse duration causes a compression of the energy and as a result - an increase in the load power.

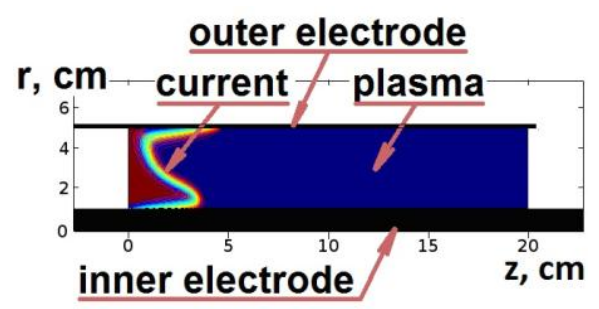

Fig. 1. POS is a plasma bridge

between two electrodes in vacuum coaxial line

The main element of the POS is a plasma bridge with a current - a nonstationary, highly nonlinear object. Its spatio-temporal dynamics is determined by the initial conditions and the current flow through the plasma. The only way to control the processes in the plasma bridge is the proper choice of the initial conditions - the plasma density, conductivity and composition, their initial spatial distribution, the dimensions of the cathode, anode, and the length of the plasma bridge, as well as the rise rate of the current through the plasma bridge. Despite many years of using POS, their experimental and theoretical studies [1 - 9], presently there is no complete theory, let alone computational models for predicting the POS parameters.

Usually, the plasma density $n_{e}$, which is provided by Bostic type plasma guns, lies in the range of $10^{12} \ldots 10^{15} \mathrm{~cm}^{-3}$, the cathode radii $R_{c}$ are $1 \ldots 5 \mathrm{~cm}$, the anode radii $R_{a}$ are $4 \ldots 10 \mathrm{~cm}$, i.e., the characteristic distances between the cathode and the anode $a$ are $3 \ldots .5 \mathrm{~cm}$. The composition of the plasma can be different, but in most cases it is a plasma that contains carbon ions, charge $Z=1 \ldots 3$. In this range of parameters $m_{e} c^{2} / e^{2}<n_{e} a^{2}<M_{i} c^{2} / Z e^{2}$, where $m_{e}-$ electron mass; $M_{i}$ - ion mass; $c$ is the speed of light, i.e. the plasma and electromagnetic field dynamics in a POS is described by electron magnetohydrodynamics (EMHD) [6]:

$$
\begin{aligned}
& \vec{E}=-\frac{\left[\overrightarrow{V_{i}} \times \vec{B}\right]}{c}+\frac{1}{e n_{e} c}[\vec{j} \times \vec{B}]+\frac{\vec{j}}{\sigma}, \\
& \vec{J}=\frac{c}{4 \pi} \operatorname{rot} \vec{H}, \\
& \frac{\partial \vec{B}}{\partial t}=-c \cdot \operatorname{rot} \vec{E},
\end{aligned}
$$

where $\vec{E}, \vec{H}$ are the strength of the electric and magnetic fields; $\vec{j}$ is the electron current density; $\sigma$ is the plasma conductivity. Eq. (1) is the electron fluid motion equation under the assumption of strong collisions, when the inertia of the electrons can be neglected, and when the magnetic pressure significantly exceeds the thermal pressure. Eq. (2) is the Ampere's law in which the displacement current is omitted, and Eq. (3) is the Faraday's law. Plasma is assumed quasineutral $n_{e}=Z n_{i}$. Eqs. (1) - (3), excluding $\vec{j}$ and $\vec{E}$, can be reduced to:

$$
\frac{\partial \vec{B}}{\partial t}+\frac{c}{4 \pi} \operatorname{rot}\left\{\frac{[\operatorname{rot} t \vec{B} \times \vec{B}]}{e n_{e}}+\frac{c}{\sigma} \operatorname{rot} \vec{B}\right\}=\operatorname{rot}\left[\vec{V}_{i} \times \vec{B}\right],
$$

which, under the assumption of $\sigma \neq f(r, z)$, has the form: 


$$
\frac{\partial \vec{B}}{\partial t}=\operatorname{rot}\left[\vec{V}_{i} \times \vec{B}\right]-\operatorname{rot}\left[\frac{c}{4 \pi e n_{e}} \operatorname{rot} \vec{B} \times \vec{B}\right]+\frac{c^{2}}{4 \pi \sigma} \Delta \vec{B}
$$

The first term on the right-hand side of (5) describes the acceleration of the plasma as a whole, the characteristic velocity scale for this is the Alfvén velocity: $V_{A}=B / \sqrt{4 \pi n_{i} M_{i}}$. The second term in (5) is responsible for the rapid penetration of the magnetic field into the plasma in the form of a quasi magnetostatic wave (KMC means Kingsepp, Mokhov, and Chukbar (KMCwave), [5]) with a velocity [6, 7]: $u_{f}=c B r^{2} / 8 \pi e \cdot \partial / \partial r\left(1 / n_{e} r^{2}\right)$. The third term in (5) describes the diffuse penetration of a magnetic field into a plasma. Typical speeds can be estimated as: $V_{A o}=4.36 \cdot 10^{10} I / r \sqrt{M_{i} / m_{p} \cdot n_{e} / Z}, u_{f o}=9.94 \cdot 10^{17} I / n_{e} r^{2}$, where $V_{A o}, u_{f o}$ are in $\mathrm{cm} / \mathrm{s} ; r-$ in $\mathrm{cm} ; I-$ in A; $n_{e}-$ in $\mathrm{cm}^{-3}$. For $I=100 \mathrm{kA} ; R_{c}=2 \mathrm{~cm} ; M_{i} / m_{p}=12$; $Z=1 ; n_{e}=10^{14} \mathrm{~cm}^{-3}$; we have: $V_{A o}=0.63 \cdot 10^{8} \mathrm{~cm} / \mathrm{s}$; $u_{f o}=2.49 \cdot 10^{8} \mathrm{~cm} / \mathrm{s}$. I.e., $u_{f o} \gg V_{A o}$.

Magnetic field that propagates in a plasma with a velocity $u_{f}$ can accelerate ions at the front of the KMCwave and disturb the initial plasma density $[4,10]$. The ions speed due to such acceleration can be estimated. From the plasma momentum equation, its longitudinal component, taking into account that the gradient of magnetic pressure $\nabla\left(\vec{B}^{2} / 8 \pi\right)$ is much higher than the gradient of thermal pressure $\nabla(P)$, we have:

$$
d\left(n_{i} M_{i} V_{i z}\right) / d t \approx \nabla\left(\vec{B}^{2} / 8 \pi\right)
$$

whence $n_{i o} M_{i} V_{i z} \approx \nabla\left(\vec{B}^{2} / 8 \pi\right) \Delta t$. The characteristic time of such acceleration can be estimated as $\Delta t \approx \delta_{f} / u_{f}$, where $\delta_{f}$ is the width of the KMC-wave front, it is determined by the diffusion coefficient $D=c^{2} / 4 \pi \sigma$ (see Eq. (5)), $\delta_{f}=D / u_{f}$. The estimation for $\nabla \approx 1 / \delta_{f}$, gives for the ion velocity $V_{i z} \approx V_{A}^{2} / 2 u_{f}$, and, for the limiting case $V_{i z} \approx u_{f}$, gives $V_{i z} \approx V_{A} / \sqrt{2}$. Due to the ions acceleration, the plasma density is disturbed. Its characteristic values can be estimated from the continuity equation for the plasma density: $\left|\Delta n_{i}\right| / n_{i o} \approx V_{i z} / u_{f}$. For the plasma parameters given above, at $V_{A o}=0.63 \cdot 10^{8} \mathrm{~cm} / \mathrm{s}, u_{f o}=2.49 \cdot 10^{8} \mathrm{~cm} / \mathrm{s}$, $\left|\Delta n_{i}\right| / n_{i o} \approx 0.25$. I.e., the KMC-wave, when passing through the plasma, slightly perturbs its density.

The above estimates allow the following scenario of the POS operation [10]. When the capacitive energy storage is turned on, the current increasing in time is closed through the left boundary of the POS plasma, forming a current loop (see Fig. 1). Over time, a magnetic field in the form of a KMC-wave penetrates into the plasma at a speed of the order of $u_{f}$. At the KMCwave front, ions are accelerated to velocities $V_{i z} \leq V_{A} / \sqrt{2}<u_{f}$. The time of energy accumulation in an inductive energy storage device with POS can be estimated as the time for ions with a velocity $V_{i z} \approx V_{A} / \sqrt{2}$ to pass through a plasma bridge of length $L_{p}$. For the circuit current, which changes as $I(t)=I_{o} \sin (2 \pi t / T), \quad$ this gives: $t_{c}=\pi c L_{p} r \sqrt{\pi n_{e o} M_{i} / 2 Z} / I_{o}$. For calculations it is convenient to use $t_{c}=5.1 \cdot 10^{-11} L_{p} r \sqrt{n_{e o} M_{i} / m_{p} Z} / I_{o}$, where $t_{c}$ is in s; $L_{p}, r-$ in cm; $n_{e}-$ in $\mathrm{cm}^{-3} ; I_{o}-$ in A. For estimates, as $r$, can be chosen the average radius between the cathode and the anode, since the ion velocity is inhomogeneous along the radius. For $I=100 \mathrm{kA}$; $R_{c}=2 \mathrm{~cm} ; R_{a}=7.5 \mathrm{~cm} ; L_{p}=15 \mathrm{~cm} ; M_{i} / m_{p}=12 ; \mathrm{Z}=1$; $n_{e}=10^{14} \mathrm{~cm}^{-3}$, we have: $t_{c}=1.25 \cdot 10^{-6} \mathrm{~s}$. When the current front (current loop) moves along the plasma, the current channel gradually enters the area where the plasma density decreases towards the load. With a decrease in the plasma density, the velocity of the KMCwave increases and the magnetic field is more and more detached from the perturbed ion background, heading towards the plasma boundary. If the length of this transition area is estimated as $\delta \sim a \sim \delta_{i}=c / \omega_{p i} \quad\left(\delta_{i}>>\right.$ is a necessary condition for the application of an "ideal" EMHD with immobile ions, $\omega_{p i}$ is the ion plasma frequency), then from the expression for $u_{f}$, taking into account that $\nabla \approx 1 / \delta_{i}$, the opening time can be estimated as: $t_{s}=\delta_{i} / u_{f}=M_{i} c^{2} r / e Z I_{o}$. For calculations it is convenient to use $t_{s}=10^{-3} r \sqrt{M_{i} / m_{p}} / I_{o} Z$, where $t_{s}$ is in $\mathrm{s} ; r-$ in $\mathrm{cm} ; I_{o}-$ in A. For $I=100 \mathrm{kA} ; R_{c}=$ $2 \mathrm{~cm} ; M_{i} / m_{p}=12 ; Z=1$, this gives: $t_{s}=6.93 \cdot 10^{-8} \mathrm{~s}$. For an inductance of about $200 \mathrm{nH}$, with a full current break of $100 \mathrm{kA}, \mathrm{U}_{\mathrm{POS}}=289 \mathrm{kV}$, which corresponds to the voltage multiplication factor $\mathrm{U}_{\mathrm{POS}} / \mathrm{Uo}=11.56$ (Uo $=$ $25 \mathrm{kV}$ ). These estimates, based mainly on EMHD, are in good agreement with the experimental results [11 - 13].

Thus, the dynamics of the POS is mainly determined by the rapid penetration of the magnetic field into the plasma, the formation and movement of the current loop in it. Below the numerical simulation results for the dynamics of the magnetic field penetration into the plasma are presented. It is shown that the initial plasma density, current, and POS geometry are the most important parameters affecting the motion of the current loop in the POS plasma.

\section{EMHD EQUATIONS}

In the axially symmetric case (4) has the form:

$$
\begin{aligned}
& \frac{\partial B_{\phi}}{\partial t}+\frac{c}{4 \pi} \frac{\partial}{\partial z}\left\{-\frac{1}{e n} \frac{B_{\phi}}{r} \frac{\partial}{\partial r}\left(r B_{\phi}\right)-\frac{c}{\sigma} \frac{\partial B_{\phi}}{\partial z}\right\}+ \\
& \frac{c}{4 \pi} \frac{\partial}{\partial r}\left\{\frac{1}{e n} B_{\phi} \frac{\partial B_{\phi}}{\partial z}-\frac{c}{\sigma} \frac{1}{r} \frac{\partial}{\partial r}\left(r B_{\phi}\right)\right\}=-\frac{\partial}{\partial z}\left(V_{z} B_{\phi}\right)-\frac{\partial}{\partial r}\left(V_{r} B_{\phi}\right) .
\end{aligned}
$$

It is convenient in (6) to replace $H=-r \cdot B_{\phi}$, and pass to dimensionless variables $z=\tilde{z} \cdot R_{c} ; r=\widetilde{r} \cdot R_{c}$; $t=\tilde{t} \cdot T_{A} ; n=\tilde{n} \cdot n_{o} \cdot \delta_{i} / R_{c} ; \sigma=\sigma_{1} \cdot T_{o}^{3 / 2} \cdot \widetilde{T}^{3 / 2} ; T_{o}-$ 
initial electron temperature; $H=\widetilde{H} \cdot H_{o} ; H_{o}=2 \cdot I_{o} / c$; $V_{r, z}=\tilde{V}_{r, z} \cdot V_{A}$. As a result, omitting the tildes, we have:

$$
\frac{\partial H}{\partial t}+\frac{1}{r} \frac{\partial}{\partial r}\left\{r \Gamma_{r}\right\}+\frac{\partial}{\partial z}\left\{\Gamma_{z}\right\}=\frac{2 \Gamma_{r}}{r}-\hat{G},
$$

where $\Gamma_{z}=\frac{H}{n r} \frac{\partial H}{\partial r}-\frac{\xi}{T^{3 / 2}} \frac{\partial H}{\partial z}$;

$\Gamma_{r}=-\frac{H}{n r} \frac{\partial H}{\partial z}-\frac{\xi}{T^{3 / 2}} \frac{\partial H}{\partial r} ; \hat{G}=\frac{\partial}{\partial z}\left(V_{z} H\right)+r \frac{\partial}{\partial r}\left(\frac{V_{r} H}{r}\right) ;$

$\xi=\frac{\delta_{i}}{R_{c}} \frac{1}{\omega_{H e} \tau_{e}} ; \quad \delta_{i}=\frac{c}{\omega_{p i}}-$ ion skin length;

$\tau_{e}=\frac{3 \sqrt{m_{e}} T_{e}^{3 / 2}}{4 \sqrt{2 \pi} \Lambda e^{4} Z^{2} n_{i}}-$ electron-ion collisions time;

$\Lambda$ - Coulomb logarithm; $\omega_{\mathrm{He}}$ - electron cyclotron frequency. $H$ in (7) has the sense of a dimensionless current. Eq. (7) is written in a conservative form. The $\Gamma_{r}$ and $\Gamma_{z}$ fluxes contain two terms - the nonlinear terms are responsible for the convective propagation of the magnetic field in the plasma due to electron current, and the linear terms describe the diffuse penetration of the magnetic field into the plasma. The chosen system of dimensionless variables led to the fact that (7) contains one dimensionless parameter $\xi$. For POS in the range of parameters $n_{e}=\left[10^{12}, 10^{14}\right] \mathrm{cm}^{-3} ; M_{i} / m_{p}=12$; $Z=[1,3] ; T_{o}=[1,10] \mathrm{eV} ; I_{o}=[50,200] \mathrm{kA} ; \xi=\left[10^{-4}\right.$, $\left.10^{-1}\right]$. Further, in all computer simulations, taking into account that $V_{i}<<u_{f}$, in (7) we neglect the terms that contain the ion velocities $(\hat{G})$.

On the left boundary of the plasma (see Fig. 1), the boundary condition for (7) is determined by the magnetic field, which is created by the current passing through the cathode. On the right boundary, the magnetic field is equal to zero, and on the inner and outer metal electrodes of the coaxial POS, the z-component of the electric field is zero. If the total current is presented as $I(t)=I_{o} f(t)$, then $H(r, z=0)=f(t)$. All simulations below were performed with $f(t)=1$. On the right boundary of the POS plasma the boundary condition for (7) has the form: $H\left(r, z=L_{p} / R_{c}\right)=0$. On the inner and outer electrodes the boundary condition for (7) has the form: $\quad \Gamma_{r}(r=1, z)=0 \quad$ (inner), $\quad \Gamma_{r}\left(r=R_{a} / R_{c}, z\right)=0$ (outer).

Eq. (7) is the scalar convective-diffuse equation, for which, when solving it by the classical Galerkin method, it is necessary to satisfy the stability criterion: $P e=|\vec{u}| h / 2 D<1$, where $h<1$ is the grid element size, $D=\xi / T^{3 / 2} \ll<1$, $\vec{u}=\left\{u_{r}, u_{z}\right\}=\{-\partial H / \partial z /(n r), \partial H / \partial r /(n r)\}$. If the stability criterion is not satisfied, i.e., the Peclet number $P e>1$, then nonphysical numerical oscillations can arise on the solutions $H(r, z)$, which, in the case of a nonlinear convective-diffusion equation, can grow indefinitely. Usually, to suppress numerical oscillations, various methods of stabilization [14 - 16], or adaptive meshes [17] are used. In this study, we used the methods described in $[15,16]$.

ISSN 1562-6016. BAHT. 2021. №6(136)

\section{NUMERICAL SIMULATION RESULTS}

Fig. 2 shows the simulation results for Eq. (7) with $n_{e}=10^{14} \mathrm{~cm}^{-3} ; I_{o}=100 \mathrm{kA} ; M_{i} / m_{p}=12 ; Z=1$. Plasma density is homogeneously distributed in space. With these parameters $\xi=2.17 \cdot 10^{-3}$, i.e., the magnetic field upon penetration into the plasma should have a sufficiently sharp front, the width of which is proportional to $\xi$. Fig. 2 shows, at different times, current density $\vec{j}=\left\{j_{r}, j_{z}\right\}, \phi-$ component of $\vec{B}(r, z)$. The current density $\vec{j}$ is also shown by arrows.

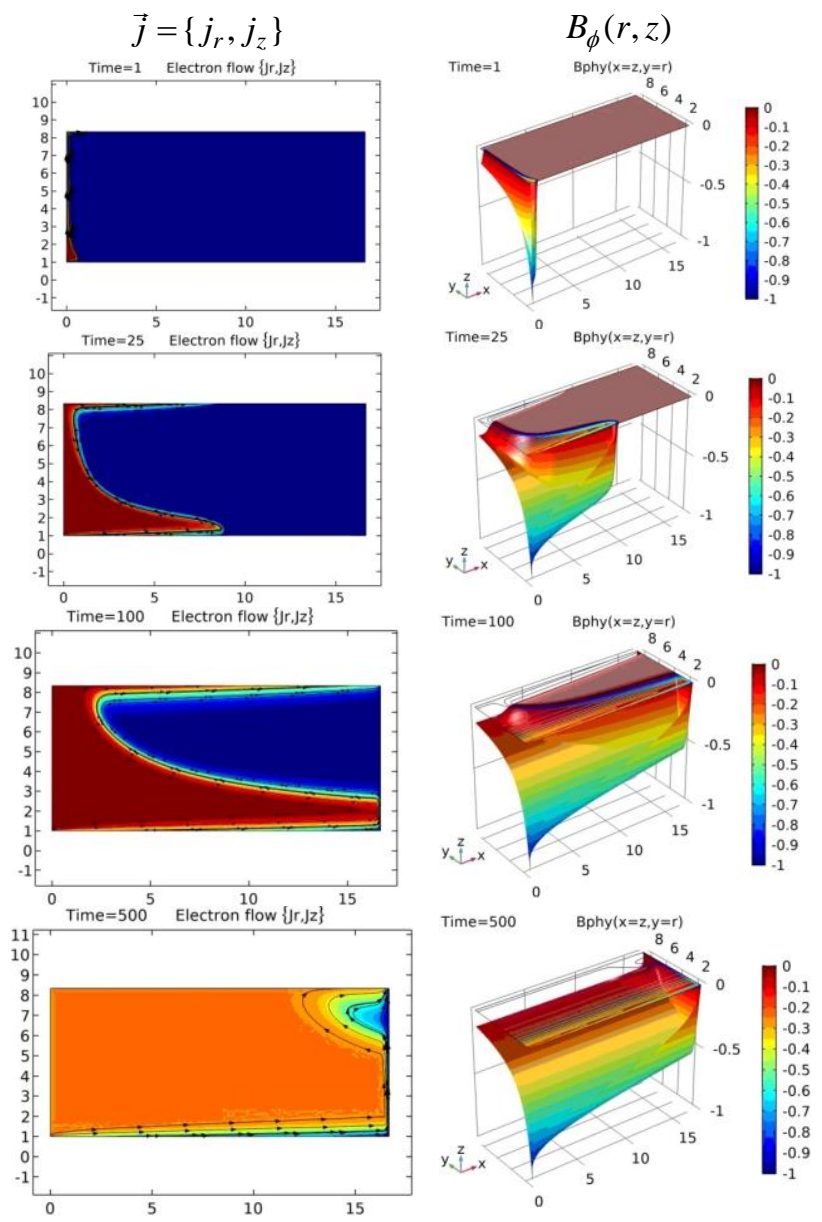

Fig. 2. Spatio-temporal dynamics of magnetic field penetration into the POS's plasma. Plasma density is homogeneously distributed in space

As can be seen from Fig. 2, over time, the magnetic field $\vec{B}(r, z)$ penetrates into the plasma. This penetration occurs in the form of a radially inhomogeneous KMC-wave with a sharp front, it is faster than the diffusive penetration. Since $\vec{B}(r, z)$ and $\vec{j}(r, z)$ are related by equation (2), the highest current density $\vec{j}$ is where the spatial derivatives of $\vec{B}(r, z)$ are maximal, i.e., at the front of the KMC-wave: $j_{r} \sim \partial B_{\phi} / \partial z$, $j_{z} \sim \partial\left(r B_{\phi}\right) / \partial r / r$. As can be seen from the expression for $j_{r}$, the current density in the cathode-anode direction is determined by the magnetic field change rate in the longitudinal direction $-j_{r} \sim \partial B_{\phi} / \partial z$. That is, the faster $B_{\phi}$ changes in the longitudinal direction, the 
higher current density flows in the transverse direction. The maximum inhomogeneity of $B_{\phi}$ in the longitudinal direction is determined by the width of the KMC-wave front, i.e., by the parameter $\xi$. The same is true for the current density $j_{z}$ in the longitudinal direction.

The electron current density $\vec{j}$ is pressed to the electrodes (see Fig. 2), i.e., electrons leave the cathode and enter the anode almost tangentially. This is due to the fact that on metal electrodes $E_{z}=0$. Taking this into account, from (1), for $\vec{V}_{i}=0$, it is easy to obtain $j_{r} / j_{z}=1 /\left(\omega_{H e} \tau_{e}\right)<<1$, i.e., indeed electrons leave the cathode and enter the anode almost tangentially.

It is seen from Fig. 2, that the longitudinal velocity of magnetic field penetration into a plasma, as well as the velocity of the current loop in the longitudinal direction, strongly depends on the transverse coordinate even for a homogeneous plasma. Far from the electrodes, where their influence is insignificant, for a homogeneous plasma we have: $u_{f}=c B_{\phi} /\left(4 \pi e n_{e o} r\right)$. Taking into account that, as follows from (2), $B_{\phi} \sim 1 / r$, it is clear that in the middle of the plasma filled gap, far from the cathode and anode, the longitudinal velocity of the magnetic field penetration into the plasma and the velocity of the current loop will decrease with increasing radius. The strong dependence of the current loop longitudinal velocity on the transverse coordinate, together with the influence of the boundary conditions at the cathode and anode $\left(j_{r} / j_{z}<<1\right)$, lead to the formation of an S-shaped current loop even in a homogeneous plasma. The characteristic width of the current loop is $\sim \xi / u_{f}$. Simulations show that its velocity is proportional to the current $I_{o}$ and inversely proportional to the plasma density $n_{e}$, which is in good agreement with the expression for the KMC-wave velocity.

According to (1), the electric field $\vec{E} \sim \vec{j}$. I.e., it has a maximum value in a narrow area around the current loop. As can be seen from Fig. 3, the $E_{z}(r, z)$ field is always greater than zero. It accelerates ions in the positive direction of the $z$ axis, towards the load. The $E_{r}(r, z)$ field (see Fig. 3) accelerates ions to both the cathode and the anode.

Fig. 4 shows, in dimensionless variables, the force $\vec{F}=-\nabla\left(\vec{B}^{2} / 8 \pi\right)+(\vec{B} \nabla) \vec{B} / 4 \pi$, which is included in the MHD equations [18]. As can be seen from Fig. $4, F_{z}$ accelerates the plasma towards the load, and $F_{r}$ pushes it to the cathode and anode. It is also seen that $\vec{F}$ is concentrated in a narrow area around the current loop. I.e., the above estimates for the ion velocity due to the interaction with the KMC-wave, the perturbation of the plasma density, as well as the time of energy accumulation in the inductive energy storage with POS, don't contradict not only the known experiments, but also the given numerical simulations.

An important POS characteristic is its resistance $R$ at the stage of energy storage. It should be as low as possible, less than the resistance of the energy storage circuit. This is necessary in order for the POS to act as a current switch, and has little effect on the energy storage process.
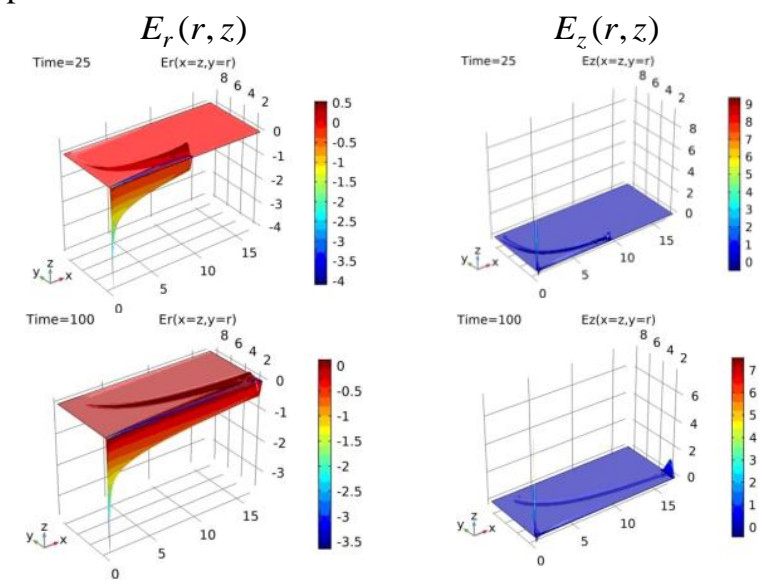

Fig. 3. Spatio-temporal dynamics of electric field penetration into the POS's plasma
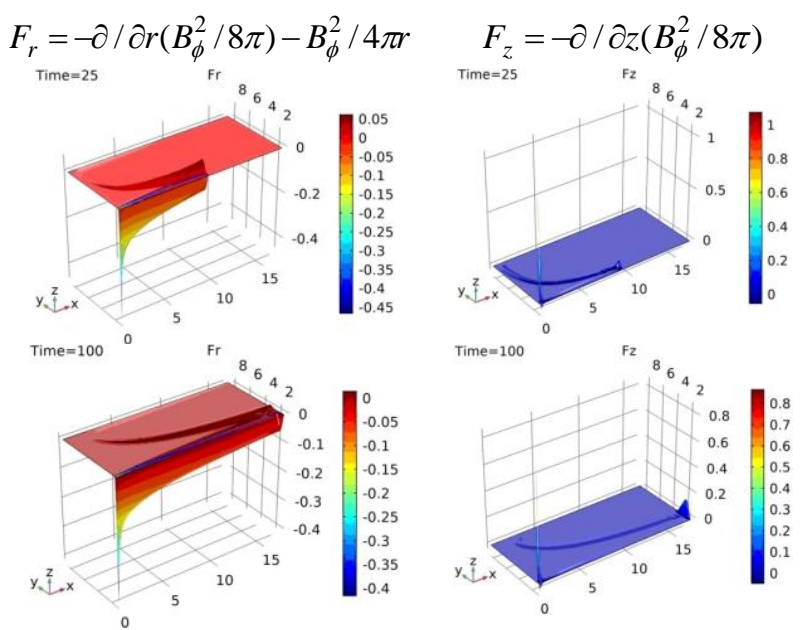

Fig. 4. Spatio-temporal dynamics of $\vec{F}=-\nabla\left(\vec{B}^{2} / 8 \pi\right)+(\vec{B} \nabla) \vec{B} / 4 \pi$ in the POS's plasma

The POS resistance can be estimated from the following considerations [19]. For a POS plasma bridge with a radius $r$ and a length $L_{p}$, the magnetic energy flux that is transferred from the cathode to the anode can be estimated as $P=B_{\phi}^{2} / 8 \pi \cdot v_{e} 2 \pi r L_{p}$, where $v_{e}=I / e n_{e} 2 \pi r L_{p}$ is the electron current velocity. Hence $P=B_{\phi}^{2} / 8 \pi \cdot I / e n_{e}$, i.e., the magnetic energy flux does not explicitly depend on the dimensions of the POS plasma. As $B_{\phi}=2 \mathrm{I} / \mathrm{cr}$, we have for $P=I^{2} u / c^{2}$, where $u=I / e n_{e} 2 \pi r^{2}$ is the electron current velocity averaged over the length of the order of $r$. Hence, for $R$ we have: $R=P / I^{2}=u / c^{2}$. For calculations it is convenient to use $R=30 u / c$, where $R$ is in $\Omega$. For $u$ in the range of $10^{7} \ldots 10^{8} \mathrm{~cm} / \mathrm{s}$, the resistance $R$ is in the area $10^{-2} \ldots 10^{-1} \Omega$. So, the POS resistance depends on the control parameters as follows: $R \sim 1 / n_{e}, R \sim I, R \sim 1 / r^{2}$. In the latter expression, the value of $r$ is not exactly defined, nevertheless $R_{c}<r<R_{a}$. In the numerical solution of equation (7), at each moment of time, $B_{\phi}(r, z), v_{e r}(r, z)=j_{r} / e n_{e}$ are known. Therefore, it is possible to calculate the magnetic energy flux, which is entered into the plasma ISSN 1562-6016. BAHT. 2021. №6(136) 
by the electron current through the cathode $P_{\text {in }}=\int_{0}^{L_{p}} \frac{B_{\phi}^{2}\left(R_{c}, z\right)}{8 \pi} \frac{j_{r}\left(R_{c}, z\right)}{e n_{e}\left(R_{c}, z\right)} 2 \pi R_{c} d z$, and magnetic energy flux that is carried out of the plasma by an electron current through the anode $P_{\text {out }}=\int_{0}^{L_{\phi}} \frac{B_{\phi}^{2}\left(R_{a}, z\right)}{8 \pi} \frac{j_{r}\left(R_{a}, z\right)}{e n_{e}\left(R_{a}, z\right)} 2 \pi R_{a} d z$, and calculate the resistance as $R=\left(P_{\text {in }}-P_{\text {out }}\right) / I^{2}$. There is no magnetic energy flux through the left boundary of the plasma, since $j_{z} \sim \partial\left(r B_{\phi}\right) / \partial r$ and $B_{\phi}(r, z=0)=2 I / c r$, therefore the derivative $\partial / \partial r$ is zero, and through the right boundary, since $B_{\phi}\left(r, z=Z_{p}\right)=0$. The results of the POS resistance calculation are shown in Figs. 5-7 for different cathode radii, plasma density $n_{e o}=10^{12} \ldots 10^{15} \mathrm{~cm}^{-3}$, current $I_{o}=50 \ldots 200 \mathrm{kA}, M_{i} / m_{p}=12$ (carbon), the charge of carbon ions $Z=1$. Plasma density is uniformly distributed in space.

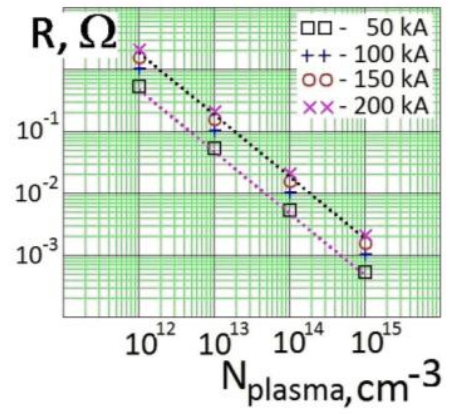

Fig. 5. The POS resistance vs plasma density. Straight lines are an approximation of the dependence $R\left(n_{e}\right)$ by the function $a / n_{e}$

As can be seen from Fig. 5, regardless of the total current $I_{o}$, the POS resistance $R \sim 1 / n_{e}$, which corresponds to the above estimates. For the studied plasma densities, the POS resistance $R$ is in the range of $10^{-3} \ldots 1 \Omega$.

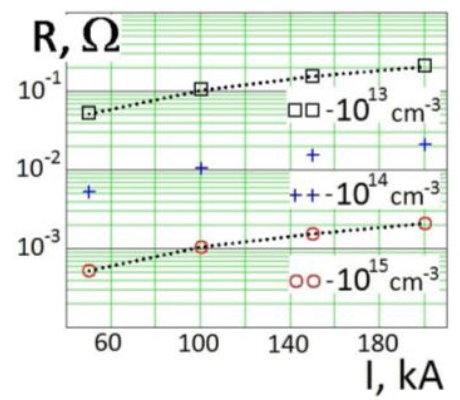

Fig. 6. The POS resistance vs current $I_{o}$.

Lines are an approximation of the dependence $R\left(n_{e}\right)$ by the function $R\left(I_{o}\right)=b I_{0}$

As can be seen from Fig. 6, regardless of the plasma density $n_{e o}$, the POS resistance $R \sim I_{o}$, which corresponds to the above estimates too.

As can be seen from Fig. 7, the POS resistance decreases with the cathode radius as $R \sim 1 / R_{c}^{2.4}$, which is little bit faster than in the above theoretical estimation.

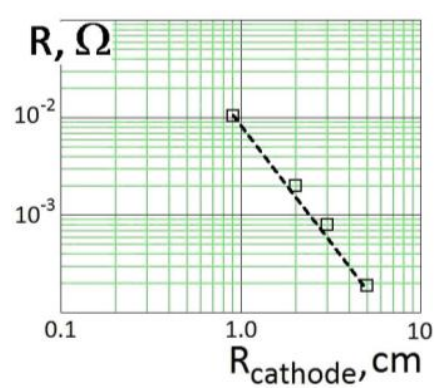

Fig. 7. The POS resistance vs cathode radius $R_{c}$. Line is an approximation of the dependence $R\left(R_{c}\right)$ by the function $R\left(R_{c}\right)=c / R_{c}^{2.4}$

\section{CONCLUSIONS}

Computer simulations of the magnetic field penetration into the POS plasma, in the EMHD approximation, show that the magnetic field penetrates the plasma in the form of a wave with a narrow front. Since the electron current density is proportional to the spatial derivatives of the magnetic field, at the front of this wave the current density is maximum, which leads to the formation of a current loop in the POS plasma, thats transfers the charge from the cathode to the anode. The strong dependence of the longitudinal velocity of the current loop on the transverse coordinate, as well as the influence of the boundary conditions at the POS cathode and anode, lead to the formation of a narrow S-shaped current loop even in a spatially homogeneous plasma. The control parameters affecting the dynamics of the magnetic field and the motion of the current loop in the POS plasma are the initial plasma density, the total current, and the POS geometry. For a wide range of initial plasma densities, total currents and cathode radii, the POS resistance $R$ was calculated. It turned out that $R \sim 1 / n_{e}, R \sim I_{o}, R \sim 1 / R_{c}^{2.4}$, and it is in the range of $10^{-3} \ldots 1 \Omega$ for usual POS parameters.

\section{REFERENCES}

1. C.W. Mendel, S.A. Goldshtein. A fast opening switch for use in REB diode experiments // Journal of Applied Physics. 1977, v. 48, p. 1004-1007.

2. P.F. Ottinger, S.A. Goldshtein, R.A. Meger, et al. Theoretical modeling of the plasma erosion opening switch for inductive storage applications // Journal of Applied Physics. 1984, v. 56, p. 774-784.

3. R.A. Meger, R.J. Commisso, G. Cooperstein, S.A. Goldstein. Vacuum inductive store/pulse compression experiments on a high power accelerator using plasma opening switches // Applied Physics Letters. 1983, v. 42, p. 943-949.

4. A. Fruchtman, L.I. Rudakov. Two-dimensional fast penetration of a magnetic field into a homogeneous plasma // Physical Review Letters. 1992, v. 69, p. 2070-2073.

5. A.S. Kingsepp, Yu.V. Mokhov, K.V. Chukbar. Nonlinear skin effects in a plasma // Soviet Journal of Plasma Physics. 1984, v. 10, p. 495-499.

6. A.V. Gordeev, A.S. Kingsep, L.I. Rudakov. Electron magnetohydrodynamics // Physics Reports. 1994, v. 243 , p. $215-315$. 
7. K.V. Chukbar. Lectures on transport phenomena in plasma. Dolgoprudny: Intellect Publishing House, 2008, 256 p.

8. G.I. Dolgachev, E.D. Kazakov, Yu.G. Kalinin, et al. RS-20MR high-current relativistic electron beam generator based on a plasma opening switch and its applications // Plasma Physics Reports. 2019, v. 45, p. 315-324.

9. S.V. Loginov. Experimental investigation of voltage scaling in a plasma switch // Russian Physics Journal. 2020, v. 62, p. 1976-1981.

10. A.S. Chuvatin, L.I. Rudakov, B. Etlicher. Interaction of a fast magnetic field with nonmagnetized plasma for the POS case // Proc. 11th Inter. Conf. HighPower Particle Beams, Prague, Czech Rep. 1996, p. 1199-1202.

11. E.I. Skibenko, V.B. Yuferov. Small-size directaction electron accelerator with a high-efficiency nanosecond plasma-current switch // Problems of Atomic Science and Technology. Series "Plasma Electronics and New Methods of Acceleration". 2019, № 4, p. 10-14.

12. V.B. Yuferov, E.I. Skibenko, I.N. Onishchenko, V.G. Artyuch, O.S. Druy. Investigation of highcurrent plasma opening switch at low gas pressure // Problems of Atomic Science and Technology. Series
“Nuclear Physics Investigations”. 2000, № 2, p. 100-102.

13. V.G. Artyukh, E.I. Skibenko, Yu.V. Tkach, V.B. Yuferov. Study of a high-current plasma opening switch: Preprint KIPT 89-28. Kharkov: KIPT, 1989, $12 \mathrm{p}$.

14. O.C. Zienkiewicz, R.L. Taylor, P. Nithiarasu. The finite element method for fluid dynamics. Elsevier, 2005, $400 \mathrm{p}$.

15. C. Johnson. Numerical solution of PDE by FEM. Cambridge Univ. Press, 1987, 278 p.

16. T.J.R. Hughes, A.N. Brooks. A multidimensional upwind scheme with no crosswind diffusion // In T.J.R. Hughes, editor, Finite Element Method for Convection Dominated Flows, AMD. ASME, New York, 1979, v. 34, p. 19-35.

17. W. Bangerth, R. Rannacher. Adaptive FEM for differential equations. Birkhauser Boston, 2003, 207 p.

18. A.I. Morozov. Introduction to plasma dynamics. M.: "Fizmatlit", 2006, 576 p. (in Russian).

19. K.V. Chukbar, V.V. Yan'kov. Magnetic field evolution in plasma switches // Journal of Technical Physics. 1988, v. 58, p. 2130-2135.

Article received 11.10 .2021

\section{ДИНАМИКА МАГНИТНОГО ПОЛЯ В ПЛАЗМЕННОМ КОММУТАТОРЕ ТОКА}

\section{О.В. Мануйленко, И.Н. Онищенко, А.В. Пащенко, И.А. Пащенко, В.А. Соченко, В.Г. Свиченский, В.Б. Юферов Б.В. Зайцев}

Компьютерные моделирования проникновения магнитного поля в плазму плазменного коммутатора тока (ПКТ) и формирования в ней токовой петли представлены для различных начальных плотностей плазмы, полных токов и геометрий ПКТ. Показано, что динамика токовой петли в ПКТ определяется быстрым проникновением в плазму магнитного поля за счет эффекта Холла. Сильная зависимость продольной скорости токовой петли от поперечной координаты, а также влияние граничных условий на катоде и аноде ПКТ приводят к образованию узкой S-образной токовой петли в однородной плазме. Показано, что управляющими параметрами, влияющими на динамику магнитного поля и движение токовой петли в ПКТ, являются начальная плотность плазмы, полный ток и радиус катода. Сопротивление ПКТ рассчитано для широкого диапазона начальных плотностей плазмы, полных токов и радиусов катода. Показано, что сопротивление ПКТ пропорционально полному току, обратно пропорционально плотности плазмы и находится в диапазоне $10^{-3} \ldots 1$ Ом для плотностей плазмы $10^{12} \ldots 10^{15} \mathrm{~cm}^{-3}$.

\section{ДИНАМІКА МАГНІТНОГО ПОЛЯ У ПЛАЗМОВОМУ КОМУТАТОРІ СТРУМУ}

\section{О.В. Мануйленко, І.М. Оніщенко, А.В. Пащенко, І.А. Пащенко, В.А. Сошенко, В.Г. Свіченський, В.Б. Юферов, Б.В. Зайцев}

Комп'ютерні моделювання проникнення магнітного поля у плазму плазмового комутатора струму (ПКС) i формування у ній струмової петлі представлені для різних початкових густин плазми, повних струмів $\mathrm{i}$ геометрій ПКТ. Показано, що динаміка струмової петлі у ПКС визначається швидким проникненням магнітного поля у плазму за рахунок ефекту Холла. Сильна залежність поздовжньої швидкості струмової петлі від поперечної координати, а також вплив граничних умов на катоді і аноді ПКТ призводять до утворення вузької S-образної струмової петлі в однорідній плазмі. Показано, що керуючими параметрами, що впливають на динаміку магнітного поля і рух струмової петлі у ПКТ, є початкова густина плазми, повний струм і радіус катода. Опір ПКТ розраховано для широкого діапазону початкових густин плазми, повних струмів і радіусів катода. Показано, що опір ПКТ пропорційний повному струму, обернено пропорційний густині плазми і знаходиться у діапазоні $10^{-3} \ldots 1$ Ом для густин плазми $10^{12} \ldots 10^{15} \mathrm{~cm}^{-3}$. 